\title{
PRODUÇÃO E ANÁLISE DE RECURSOS DIDÁTICOS PARA ENSINAR ALUNOS COM DEFICIÊNCIA VISUAL O CONTEÚDO DE MITOSE: UMA PRÁTICA PEDAGÓGICA NO ENSINO DE CIÊNCIAS BIOLÓGICAS
}

\author{
Natielle Rangel Lopes', Lorena Alves Almeida², Manuella Villar Amado³ \\ Programa de Pós-graduação em Educação em Ciências e Matemática \\ Instituto Federal do Espírito Santo - Campus Vitória \\ Avenida Vitória, 1729 - Jucutuquara, Vitória, Espírito Santo. CEP 29040780.
}

\begin{abstract}
RESUMO
Visando elaborar um recurso didático capaz de incentivar a abstração pelos alunos deficientes visuais e de atuar na promoção de uma sala de aula inclusiva, onde alunos videntes e nãovidentes acompanhem o mesmo conteúdo, propôs-se a confecção de modelos táteis/visuais, no caso deste trabalho, abordando o conteúdo de mitose. Além das diferentes texturas, buscou-se a utilização de materiais de fácil manipulação e que fossem acessíveis para a maioria dos professores, haja visto que um dos objetivos do trabalho é a reprodução dos modelos por parte dos professores em escolas com alunos deficientes visuais. Os modelos confeccionados foram aplicados para uma aluna deficiente visual de uma escola estadual na cidade de Vila Velha, no Espírito Santo. Foi possível analisar se os materiais utilizados proporcionavam sensações táteis capazes de diferenciar as estruturas, sendo aplicável como recurso didático de apoio ao professor no processo de ensino do conteúdo de mitose.
\end{abstract}

Palavras-chave: ensino de biologia; material inclusivo; divisão celular.

\begin{abstract}
Aiming to develop a teaching resource able to encourage abstraction by visually impaired students and act in promoting inclusive classroom where students seers and non- seers follow the same content, we proposed the making of tactile / visual models, case of this work , addressing the content of mitosis. Besides the different textures, we sought to use materials that were easy to handle and affordable for most teachers, given the fact that one of the goals is to reproduce the models by teachers in schools with visually impaired students. The readymade models were applied to a visually impaired student in a state school in the town of Vila Velha , Espírito Santo . It was possible to examine whether the materials afforded tactile sensations capable of differentiating structures and is applicable as a teaching resource teacher support in the teaching of the content of mitosis .
\end{abstract}

Keywords: biology education; inclusive teaching material; cell division.

\footnotetext{
1 Aluna de IC pelo Instituto Federal do Espírito Santo. Graduanda em Ciências Biológicas pela Universidade Federal do Espírito Santo. E-mail: nati.rlopes@hotmail.com

2 Aluna de IC pelo Instituto Federal do Espírito Santo. Graduanda em Ciências Biológicas. Faculdade Católica Salesiana do Espírito Santo. E-mail: lorenaalves.bio@gmail.com

${ }^{3}$ Professora de Ciências Biológicas, Doutora em Biotecnologia. Ifes - Campus Vila Velha. Docente do Programa de Pós-graduação em Educação em Ciência e Matemática do Instituto Federal do Espírito Santo. E-mail: manuellaamado@gmail.com
} 


\section{INTRODUÇÃO}

Uma das principais dificuldades no ensino de biologia está no fato de seu conteúdo estar amplamente inserido no mundo microscópio, o que torna difícil a compreensão pelo estudante (MAIA et al., 2008 ). Portanto, pode-se dizer que temas como citologia e genética exigem grande capacidade de abstração por parte dos alunos e, dessa forma, exigem um trabalho docente esclarecedor aliado a recursos didáticos capazes de auxiliar o professor no processo de ensino. Um exemplo dessa dificuldade por parte dos alunos é demonstrada em estudo de Banet e Ayuso (1995), no qual nota-se que os estudantes não compreendiam os processos de divisão celular, localização, estrutura e função do material genético, bem como sua relação com a transmissão de caracteres hereditários. Os mesmos autores citam ainda a importância dos processos de mitose e meiose como base para o melhor entendimento dos conteúdos de genética.

Para alunos normovisuais a representação normalmente é feita por meio de figuras e imagens. No entanto, incentivar a abstração por parte de alunos deficientes visuais é algo que exige a exploração de outros recursos, muitas vezes não disponíveis ao professor. Dessa forma, alguns conceitos podem passar despercebidos aos alunos com tal deficiência. 0 conhecimento deve ser compreendido por todos os alunos. Se as informações têm importância no processo de ensino, não devem ser omitidas. Existe, então, a necessidade de elaborar recursos didáticos apoiadores para que os alunos com deficiência visual tenham acesso a estes conceitos.

O ensino da célula, por ser uma estrutura microscópica, envolve a representação como recurso didático, tanto para alunos videntes quanto para os não-videntes. Tal fato evidencia que a forma de compreensão deste "mundo microscópico" não é tão diferente entre alunos com ou sem deficiência visual. A diferença está no tipo de representação, sendo necessária a utilização de modelos táteis para auxiliar a compreensão por parte de alunos não-videntes (BATISTETI et al., 2009). Visando a promoção de um contexto inclusivo de sala de aula, onde conviveriam alunos com e sem deficiência visual, é o objetivo desse trabalho a confecção de um modelo tátil/visual de divisão celular, que permita a utilização em ambos os casos. 


\section{PROCEDIMENTOS METODOLÓGICOS}

\section{Sujeito}

0 modelo de mitose foi aplicado à uma aluna deficiente visual do $1^{\circ}$ ano do ensino médio da Escola Estadual de Ensino Fundamental e Médio Padre Humberto Piacente, localizada à Rua Ana Siqueira, s/n no bairro Alecrim, em Vila Velha-ES.

\section{Planejamento dos Modelos}

A princípio foram elaborados esquemas de cada fase, com os eventos a serem representados e os possíveis materiais utilizados, sendo que partimos do princípio que estruturas de mesma composição deveriam ser montadas com materiais de mesma textura. Além disso, o material utilizado na montagem de certa estrutura em uma determinada fase, não poderia ser alterado nas fases seguintes. Por exemplo, o material utilizado para representar o material genético na prófase deveria ser o mesmo em todas as outras fases. Um ponto relevante é a escolha de materiais de fácil manuseio e que permita a criação de moldes, visto que o objetivo é que os professores possam reproduzir os modelos sem muitas dificuldades. Cabe observar também que a proposta é de materiais de baixo custo e que possam ser facilmente encontrados.

A primeira idéia foi construir um modelo com base em EVA, pois este é facilmente encontrado em papelarias e apresenta baixo custo. Outros materiais como rolhas, canudos, miçangas, barbante, fio encapado e lixa foram propostos para algumas estruturas, no entanto, alguns destes eram difíceis de manusear e outros difíceis de encontrar. Logo, optou-se por substituir alguns dos materiais propostos por EVA com texturas diferentes, também encontrados em papelarias. Antes de confeccionar os modelos de mitose, optou-se por representar também uma célula em interfase em intensa atividade metabólica, antes da duplicação do DNA, permitindo ao deficiente visual comparar a organização das estruturas antes e após a divisão, facilitando a compreensão do conteúdo. Dessa forma, seriam 6 modelos de representação nesta primeira etapa do projeto: célula em interfase, prófase, metáfase, anáfase, telófase e citocinese.

\section{Confecção do material didático}


No primeiro momento foi construído um modelo com base em EVA, que é facilmente encontrado em papelarias e outros materiais de baixo custo como rolhas, canudos, miçangas, barbante, fio encapado e lixa. No entanto, alguns destes materias eram difíceis de manusear e outros difíceis de encontrar. Logo, optou-se por substituir a marioria dos materiais propostos por EVA com texturas diferenciadas, também encontrados em papelarias.

A confecção dos modelos explorou as diferentes texturas dos materiais empregados, além do relevo. Para a confecção das seis fases da mitose e da intérfase utilizou-se:

- 4 folhas de EVA grosso $5 \mathrm{~mm}$, sendo 3 verdes e 1 azul para diferenciar a interfase das outras fases;

- 1 folha 40x60cm de EVA atoalhado branco 1mm;

- 1 folha $40 \times 60 \mathrm{~cm}$ de EVA camurça laranja $1 \mathrm{~mm}$;

- 1 folha $40 \times 60 \mathrm{~cm}$ de EVA simples verde musgo $1 \mathrm{~mm}$;

- 1 folha lixa grão 150;

- 134 'pérolas' de bijuteria cortadas ao meio, sendo 30 na célula em interfase, 20 na prófase, 12 em cada pólo da célula em telófase e 30 em cada núcleo na citocinese;

- 1 vidro de $20 \mathrm{~g}$ de adesivo instantâneo multiuso Kreateva.

\section{Aplicação dos modelos}

No dia 17 de abril de 2012 o modelo foi aplicado a uma aluna deficiente visual, cursando o primeiro ano do ensino médio de uma escola pública localizada em Vila Velha-ES. Para tanto, o responsável pela aluna assinou um Termo de Consentimento Livre e Esclarecido (TCLE). 0 objetivo da aplicação foi verificar se as texturas utilizadas no modelo proporcionariam ao aluno não vidente a percepção de diferentes formas e estruturas.

Até o dia da aplicação, a aluna ainda não havia sido exposta ao conteúdo de divisão celular, não havendo, assim, o conhecimento acerca de muitos dos conceitos representados. Tal fato permite a avaliação do modelo baseando-se principalmente nas diferentes texturas e formatos.

No dia da aplicação, foram feitas algumas perguntas para verificar se era possível diferenciar as fases e estruturas, se havia necessidade de substituir alguns dos materiais e qual a noção da aluna sobre a divisão celular. 


\section{RESULTADOS E DISCUSSÃO}

\section{Confecção do modelo}

Na figura 1 estão os 6 modelos construídos de EVA. A primeira célula construída está representando uma interfase (A), ou seja, a célula antes de entrar em divisão, com o material genético descondensado e com presença dos nucléolos. Esta célula foi representada de cor diferente das demais, pois ainda não está em processo de divisão. Esta diferença de cor facilita a identificação pelos estudantes normovisuais, mas nada impede que seja utilizada apenas uma cor na confecção de todas as fases.

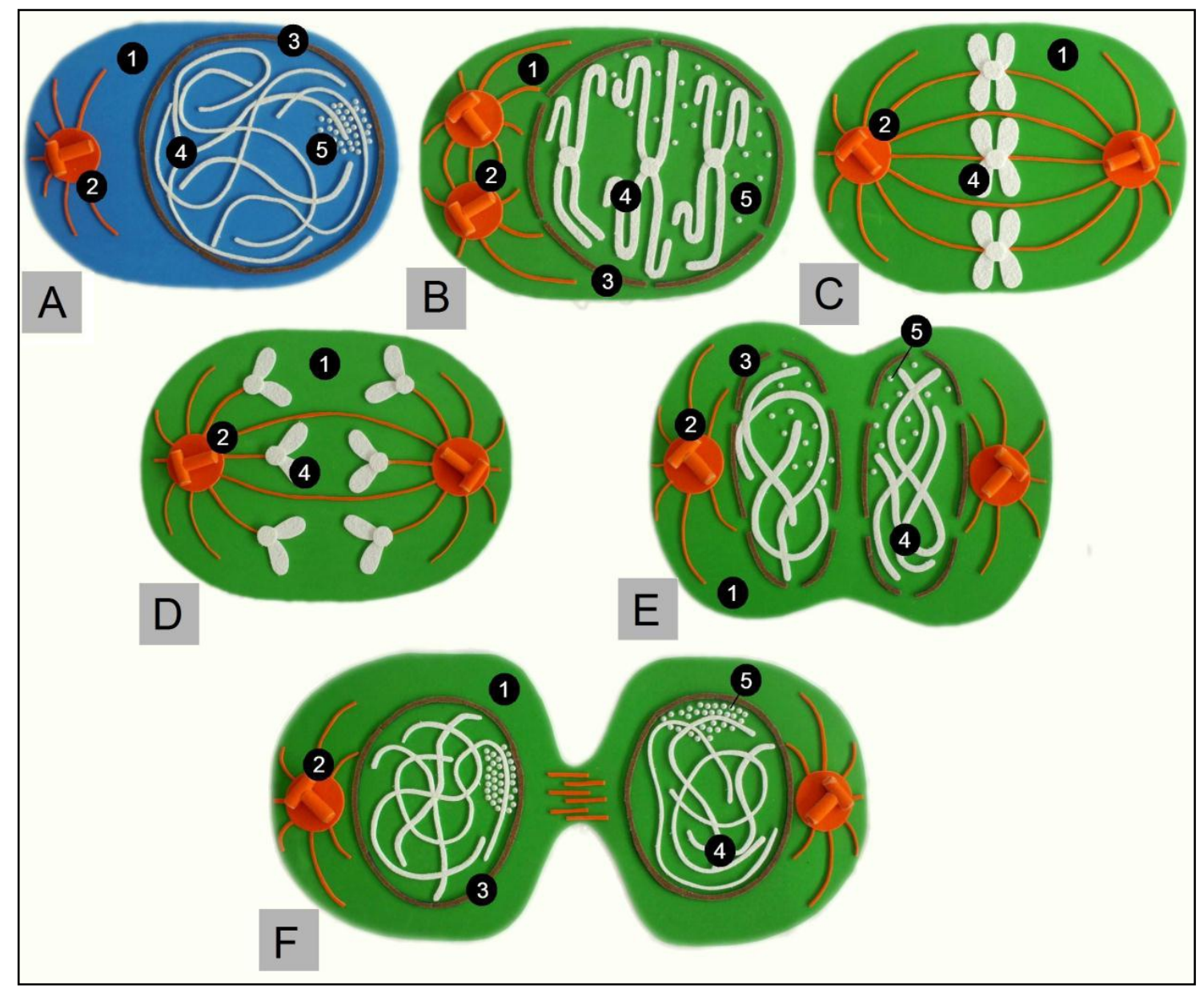

FIGURA 1: Modelos de A)Célula em interfase; B)Prófase; C)Metáfase; D)Anáfase; E)Telófase; F)Citocinese.

Em seguida, na Prófase (B), o material genético e o centríolo já estão duplicados, os cromossomos começam a se condensar, a carioteca e o nucléolo, por sua vez, começam a se desorganizar. Na Metáfase (C) os cromossomos atingem grau máximo de condensação e se 
alinham na zona mediana da célula, presos pela região do centrômero às fibras do fuso mitótico, estas são orientadas pelos centríolos que se localizam nos pólos opostos da célula. Depois, na Anáfase(D), as fibras do fuso despolimerizam-se puxando as cromátides-irmãs para pólos opostos da célula. Na Telófase (E), carioteca e nucléolo começam a se reorganizar, o material genético inicia a descondensação e o citoplasma começa a se dividir. Por último, ocorre a Citocinese (F), que é a divisão total do citoplasma formando 2 novas células, o material genético está descondensado e o nucléolo, bem como a carioteca, foram reorganizados.

Os números na imagem representam os diferentes materiais utilizados e serão descritos a seguir:

1. EVA grosso $5 \mathrm{~mm}$, utilizado para base da célula e seguindo o mesmo tamanho desde a célula em atividade até a anáfase;

2. EVA camurça, utilizado na confecção dos centríolos, das fibras do fuso e das fibras protéicas na citocinese, caracterizando estruturas do citoesqueleto celular;

3. EVA simples cortado em tiras e colado abaixo das tiras de lixa para confecção da carioteca. Proporcionando, desta forma, a sensação de uma textura diferenciada promovida pela lixa, além do relevo dado pela base de EVA;

4. EVA atoalhado, representando o material genético, cortado em tiras mais finas quando descondensado e mais espessas a medida que ocorre a condensação;

5. Pérolas de bijuteria cortadas ao meio, representando o nucléolo, coladas bem próximas nas fases em que o mesmo se encontra organizado.

Esse modelo foi construído com o objetivo de ser um material didático inclusivo, onde os alunos normovisuais e não-videntes possam participar de uma mesma atividade em sala de aula. Por isso o modelo de mitose foi confeccionado com materiais táteis e visuais diferentes e representativos em relação às estruturas e fases apresentadas.

0 passo-a-passo da montagem dos modelos segue em Anexo. 0 material permite que professores possam reproduzir os modelos e aplicá-los em sala de aula, tendo como base principalmente o EVA, um material facilmente encontrado em papelarias e que apresenta 
diversas texturas. Mesmo as outras matérias-primas utilizadas na confecção dos modelos apresentados (como a lixa, por exemplo) podem ser consideradas como acessíveis.

\section{Aplicação do modelo}

Durante a aplicação dos modelos de mitose, a aluna relatou que ao tocar os modelos era possível sentir diferentes texturas e, com isso, diferenciar as estruturas. As Figuras 2, 3, 4 e 5 a seguir são fotografias da aplicação do modelo para a aluna deficiente visual.

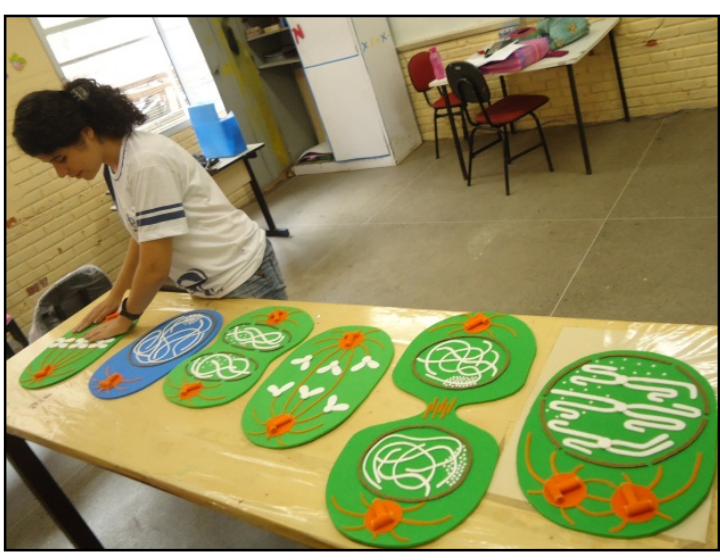

FIGURA 2: Primeiro contato da aluna com os modelos ainda desordenados.

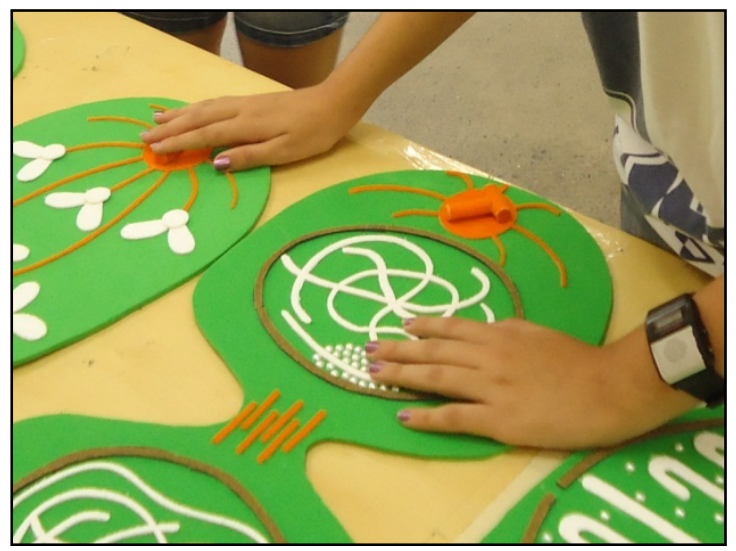

FIGURA 3: Aluna tocando centríolos e nucléolo.

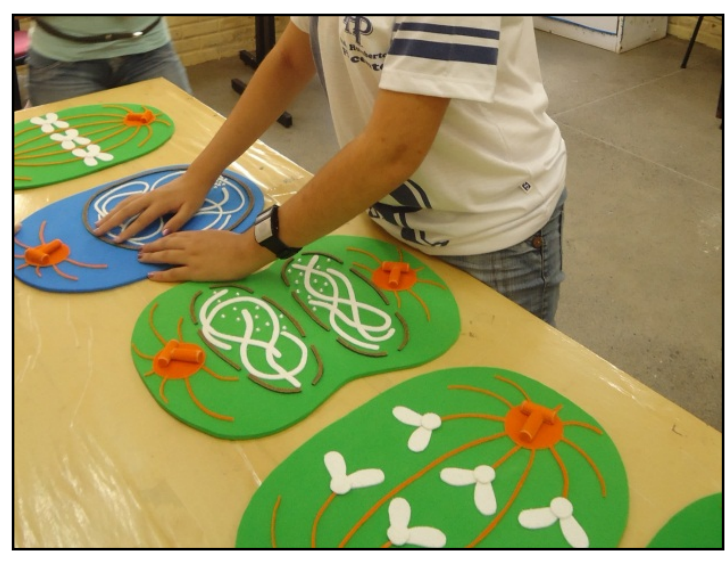

FIGURA 4: Aluna tateando a carioteca do modelo de intérfase.

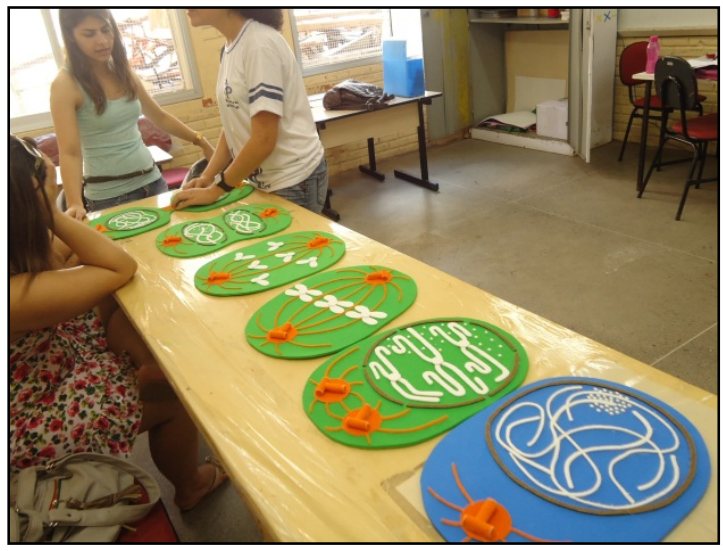

FIGURA 5: Modelos ordenados na ordem correta.

Os modelos foram organizados em uma mesa em uma ordem diferente da sequencia de etapas da mitose e pediu-se que a aluna organizasse na sequência que considerasse mais lógica, conforme observa-se na Figura 2. A ordem obtida foi: Metáfase, Anáfase, Telófase, Intérfase, Citocinese e Prófase. Notou-se então que a aluna guiava-se principalmente pelos centríolos, 
nucléolo e carioteca (FIG. 3 e 4), informando que as texturas utilizadas nessas estruturas chamavam a sua atenção.

Em seguida, os modelos foram ordenados da maneira correta (FIG. 5) e houve uma breve explicação das fases da mitose, visando esclarecer o porquê da sequência. A aluna afirmou que modelos de EVA facilitam a aprendizagem de conteúdos microscópicos e considerou que os materiais utilizados produziram resultados satisfatórios e que não há necessidade de substituição.

\section{CONSIDERAÇÕES FINAIS}

De acordo com a aplicação do modelo de mitose, houve a confirmação de que os materiais escolhidos proporcionam uma noção das diferentes estruturas, formatos e localização na célula. Portanto, o modelo construído atingiu seu objetivo de ser um material inclusivo para deficientes visuais, além de poder ser utilizado para facilitar o aprendizado da mitose por estudantes normovisuais. Sendo assim, considera-se que o material didático proposto é capaz de incentivar a abstração, sendo aplicável em um contexto de sala de aula inclusiva, auxiliando a compreensão do conteúdo de mitose.

\section{AGRADECIMENTOS}

Os autores agradecem à FACITEC pela bolsa de iniciação científica, à FAPES e ao IFES pelo financiamento do projeto, ao ILBES e à Escola Padre Humberto Piacente pelo apoio e aos alunos do PIC Jr. pela participação.

\section{REFERÊNCIAS}

BANET, E.; AYUSO, E. Introducción a la genética en la enseñanza secundaria y bachillerato: I contenidos de enseñanza y conocimientos de los alumnos. Enseñanza de las Ciencias, v.13, n.2, p.137-153, 1995.

BATISTETI, Caroline Belotto; CAMARGO, Eder Pires; ARAUJO, Elaine Sandra N. Nabuco; CALUZI, João José. Uma discussão sobre a história da ciência no ensino de célula para alunos com deficiência visual. In: ENCONTRO NACIONAL DE PESQUISA EM EDUCAÇÃO EM CIÊNCIAS, 7, Florianópolis. Anais... Florianópolis: UFSC, 2009. 
MAIA, Dayse Peixoto; MONTEIR0, Ierecê Barbosa; MENEZES, Ana Paula Sá. Diferenciando a Aprendizagem de biologia no ensino médio, através de recursos tecnológicos. In: SEMINÁRIO NACIONAL DE EDUCAÇÃO PROFISSIONAL E TECNOLÓGICA, 1, Belo Horizonte. Anais... Belo Horizonte: Cefet-MG, 2008.

PIRES, Rejane Ferreira Machado. Proposta de guia para apoiar a prática pedagógica de professores de química em sala de aula inclusiva com alunos que apresentam deficiência visual. 2010. 158 f. Dissertação (Mestrado Profissional em Ensino de Ciências - Programa de pós-graduação em ensino de ciências, Área de concentração: Ensino de Química) Universidade de Brasília, Brasília - DF, 2010. 